Original Article

\title{
Effect of Drying Temprature on some Properties of Polymer Composite with Epoxy K-153 Matrix
}

\author{
Nguyen Trung Thanh* \\ Institute of Technology, General Department of National Defence Industry, 3 Cau Vong, \\ Duc Thang, Bac Tu Liem, Hanoi, Vietnam \\ Received 20 September 2019 \\ Revised 07 November 2019; Accepted 13 April 2020
}

\begin{abstract}
The article introduces the effects of drying temperature on curing level, thermal endurance, thermal oxidation resistance, surface structure morphology of polymer composite material based on K-153 epoxy resin (K-153 epoxy resin is made from ED-20 epoxy resin modified by thiokol and oligomer acrylate), T-13 glass fiber and hardener polyethylenepolyamine. The results show that the thermal endurance, thermal oxidation resistance, surface structure morphology of polymer composite change much when the drying temperature changes. When the drying temperature increases from $60^{\circ} \mathrm{C}$ to about $80^{\circ} \mathrm{C}$, the structure of the polymer composites are tighter, the thermal endurance, thermal oxidation resistance also increases, however, if the drying temperature is continued to increase, these properties of the material will reduce.
\end{abstract}

Keywords: Polymer composite, epoxy K-153, thermal endurance, thermal oxidation resistance.

\footnotetext{
*Corresponding author.

Email address: nguyentrungthanhk42@ gmail.com

https://doi.org/10.25073/2588-1140/vnunst.4950
} 


\title{
Ảnh hưởng của nhiệt độ sấy đến một số tính chất của vật liệu polyme compozit nền epoxy K-153
}

\author{
Nguyễn Trung Thành* \\ Viện Công nghệ, Tổng cục Công nghiệp Quốc phòng, 3 Cầu Vồng, Đức Thắng, \\ Bắc Tù̀ Liêm, Hà Nội, Việt Nam \\ Nhận ngày 20 tháng 09 năm 2019 \\ Chỉnh sửa ngày 07 tháng 11 năm 2019; Chấp nhận đăng ngày 13 tháng 04 năm 2020
}

\begin{abstract}
Tóm tắt: Bài báo trình bày kết quả nghiên cứu ảnh hưởng của nhiệt độ sấy đến mức độ đóng rắn, độ bền nhiệt, độ bền oxy hóa nhiệt, hình thái cấu trúc bề mặt của vật liệu polyme compozit trên cơ sở nhựa epoxy K-153 (nhựa epoxy K-153 được chế tạo trên cơ sở nhựa epoxy ED-20 biến tính bằng thiokol và oligome acrylat) gia cường bằng sợi thủy tinh $\mathrm{T}-13$, sử dụng chất đóng rắn polyetylenpolyamin. Kết quả nghiên cứu cho thấy độ bền nhiệt, độ bền oxy hóa nhiệt, hình thái cấu trúc của vật liệu polyme compozit thay đổi nhiều khi thay đổi nhiệt độ sấy. Nhiệt độ sấy tăng từ $60^{\circ} \mathrm{C}$ lên khoảng $80^{\circ} \mathrm{C}$, cấu trúc của vật liệu polyme compozit chặt chẽ hơn, độ bền nhiệt, độ bền oxy hóa nhiệt cũng tăng lên, tuy nhiên, nếu tiếp tục tăng nhiệt độ sấy thì các tính chất này của vật liệu giảm xuống.
\end{abstract}

Tù khóa: Polyme compozit, epoxy K-153, độ bền nhiệt, độ bền oxy hóa nhiệt.

\section{Mở đầu}

Vật liệu polyme compozit (PC) nói chung và vật liệu PC trên nền nhựa epoxy nói riêng đã được nghiên cứu, ứng dụng rộng rãi trên nhiều lĩnh vực khác nhau do ưu điểm của nó như: khối lượng riêng nhỏ, độ bền cơ học cao, chịu mài mòn, chịu hóa chất tốt, bền khí hậu. Đã có nhiều nghiên cứu trong công nghệ sản xuất, chế tạo các kết cấu, chi tiết từ vật liệu PC với những hình dạng, cấu trúc và mục đích sử dụng khác nhau. Vật liệu PC đã được nghiên cứu, chế tạo và sử dụng nhiều trong thiết kế chế tạo những kết cấu hàng không, tên lửa, vũ trụ,... [1,2]. Vật liệu polyme compozit nền nhựa epoxy gia cường bằng sợi thuỷ tinh dễ dàng bị phá huỷ bởi các vết nứt ngang, vết nứt dọc và sự bóc tách giữa các lớp của vật liệu do tính giòn của nền nhựa epoxy. Các nghiên cứu gần đây chỉ ra rằng các cơ chế phá huỷ bên trong vật liệu compozit có thể từng bước được kiểm soát. Nhiều nghiên cứu đã nỗ lực cải thiện độ bền dai phá huỷ giữa các lớp, độ bền va đập của vật liệu compozit bằng cách tăng tính dai cho nhựa nền epoxy. Nhựa epoxy thông thường được dai hóa bằng một trong ba cách sau: thêm các hạt vô cơ cứng, thêm các loại cao su lỏng, thiokol hay nhựa nhiệt dẻo $[3,4]$. Tác giả A. Zubeldia và cộng sự đã nghiên cứu quá trình tách pha của polysulfit trong keo epoxy. Kết quả cho thấy sự có mặt của polysulfit làm giảm nhiệt độ thuỷ tinh hoá của nhựa epoxy, sản phẩm biến tính có khả năng bám dính tốt hơn so với nhựa epoxy không biến tính [5]. Để cải thiện tính bền dai của nhựa epoxy, các nhà sản xuất người $\mathrm{Nga}$ đã nghiên cứu sản xuất ra nhựa epoxy K-153, nhựa này được sản xuất bằng cách biến tính nhựa epoxy mac ED-20 đồng thời bằng thiokol và oligome acrylat [6]. Việc khảo sát để tìm ra nhiệt độ gia công tối ưu cho vật liệu PC trên cơ sở nhựa epoxy K-153 gia cường bằng vải thủy tinh

\footnotetext{
*Tác giả liên hệ.

Địa chi email: nguyentrungthanhk42@gmail.com

https://doi.org/10.25073/2588-1140/vnunst.4950
} 
mac $\mathrm{T}-13$ và sử dụng chất đóng rắn là polyetylenpolyamin (PEPA) hầu như chưa được đề cập. Bài báo này khảo sát ảnh hưởng của nhiệt độ sấy đến mức độ đóng rắn, độ bền nhiệt, độ bền oxy hóa nhiệt, hình thái cấu trúc của vật liệu $\mathrm{PC}$ nghiên cứu, thông qua việc khảo sát này, nhằm lựa chọn được nhiệt độ phù hợp để chế tạo vật liệu PC trên cơ sở nhựa epoxy K-153.

\section{Thực nghiệm}

\subsection{Nguyên liệu và hóa chất}

- Nhựa epoxy K-153 (Nga), hàm lượng nhóm epoxy: 19-22 \%, khối lượng phân tử 390 g/mol.

- Polyetylenpolyamin (Nga), khối lượng phân tử 230-250 g/mol, số nhóm amin bậc 3: 5-9.

- Vải thủy tinh mac T- 13 (Nga).

\subsection{Chế tạo mẫu}

- Làm sạch tấm kính, phủ chống dính lên mặt tấm kính.

- Chuẩn bị nhựa epoxy K-153 và trộn với chất đóng rắn theo tỷ lệ nhựa epoxy K-153 (100 phần khối lượng-PKL) tương ứng: PEPA (10 PKL).

- Quét lớp nhựa epoxy đã trộn với đóng rắn lên tấm kính.

- Đặt vải thủy tinh và dùng ru lô lăn để nhựa thấm đều lên lớp vải.

- Tiếp tục lăn ép nhựa và đặt vải lặp lại như trên cho đến hết lớp vải thứ 4 (mẫu vật liệu compozit đạt được chiều dày $5 \mathrm{~mm}$ ). Sau đó, sấy tấm mẫu đã gia công ở nhiệt độ $80^{\circ} \mathrm{C}$ trong thời gian 6 giờ [7].

- Kích thước mẫu 150x200 mm.

\subsection{Phương pháp thử nghiệm đánh giá}

- Xác định mức độ đóng rắn: Chuẩn bị thiết bị soxhlet, giấy lọc trước khi cân được trích ly các thành phần dễ tan bằng axeton trên dụng cụ soxhlet khoảng 3 giờ. Sau đó, sấy khô giấy lọc đến khối lượng không đổi, cho vào bình hút ẩm và tiến hành cân giấy lọc $\left(\mathrm{g}_{0}\right)$. Pha trộn nhựa epoxy và chất đóng rắn. Phết lên tờ giấy lọc một lượng nhựa đã trộn đóng rắn, cân được giá trị $\mathrm{g}_{1}$. Tiến hành sấy các mẫu ở nhiệt độ $60^{\circ} \mathrm{C}, 70^{\circ} \mathrm{C}$, $80^{\circ} \mathrm{C}, 90^{\circ} \mathrm{C}, 100^{\circ} \mathrm{C}$ trong 6 giờ, để nguội, trích ly trong axeton ở nhiệt độ phòng trong 20 giờ. Lây mẫu ra, sấy đến khi khối lượng mẫu không đổi, cân xác định được giá trị $\mathrm{g}_{2}$.

Mức độ đóng rắn $(\mathrm{G})$ được xác định theo công thức:

Trong đó:

$$
G=\frac{g_{2}-g_{0}}{g_{1}-g_{0}} .100 \%
$$

- G: Mức độ đóng rắn, \%

- $\mathrm{g}_{0}$ : Khối lượng giấy lọc khô, $\mathrm{g}$

- $\mathrm{g}_{1:}$ Khối lượng giấy lọc khô + mẫu trước khi trích ly, g

- $\mathrm{g}_{2}$ : Khối lượng giấy lọc khô + mẫu sau khi trích ly, $\mathrm{g}$

- Độ bền nhiệt: Phân tích nhiệt khối lượng (TGA) được thực hiện trên thiết bị NETZSCH TG 209F1 LIBRA tại Viện Kỹ thuật nhiệt đới, Viện Hàn lâm Khoa học và Công nghệ Việt Nam. Điều kiện đo trong khí nitơ với tốc độ nâng nhiệt $10^{\circ} \mathrm{C} /$ phút từ nhiệt độ phòng đến $600^{\circ} \mathrm{C}$.

- Độ bền oxy hóa nhiệt: Phân tích nhiệt khối lượng (TGA) được thực hiện trên thiết bị NETZSCH TG 209F1 LIBRA tại Viện Kỹ thuật nhiệt đới, Viện Hàn lâm Khoa học và Công nghệ Việt Nam. Điều kiện đo trong không khí với tốc độ nâng nhiệt $10^{\circ} \mathrm{C} /$ phút từ nhiệt độ phòng đến $600^{\circ} \mathrm{C}$.

- Hình thái cấu trúc của vật liệu polyme compozit được quan sát trên máy FESEM Hitachi S4800 (Nhật Bản) tại Viện Kỹ thuật nhiệt đới, Viện Hàn lâm Khoa học và Công nghệ Việt Nam.

\section{Kết quả và thảo luận}

3.1. Khảo sát ảnh hưởng của nhiệt độ sấy đến mức độ đóng rắn của vật liệu polyme compozit

Để xác định khảo sát ảnh hưởng của nhiệt độ sấy đến mức độ đóng rắn của vật liệu polyme compozit trên cơ sở nhựa epoxy K-153 sử dụng chất đóng rắn PEPA (tỷ lệ: 100 PKL nhựa epoxy, 10 PKL PEPA), các mẫu sau khi gia công được sấy ở các nhiệt độ: $60^{\circ} \mathrm{C}, 70^{\circ} \mathrm{C}, 80^{\circ} \mathrm{C}, 90^{\circ} \mathrm{C}$, $100^{\circ} \mathrm{C}$ trong 6 giờ. Các mẫu được ký hiệu $\mathrm{M}_{1}$, $\mathrm{M}_{2}, \mathrm{M}_{3}, \mathrm{M}_{4}, \mathrm{M}_{5}$. Ảnh hưởng của nhiệt độ sấy đến 
độ mức độ đóng rắn của vật liệu polyme compozit được thể hiện trong Bảng 1 .

Bảng 1. Ảnh hưởng của nhiệt độ đến mức độ đóng rắn của polyme compozit

\begin{tabular}{|c|c|c|}
\hline $\begin{array}{c}\text { Tên } \\
\text { mẫu }\end{array}$ & $\begin{array}{c}\text { Nhiệt độ sấy } \\
\left({ }^{\circ} \mathrm{C}\right)\end{array}$ & $\begin{array}{c}\text { Mức độ đóng rắn } \\
(\%)\end{array}$ \\
\hline M1 & 60 & 54,76 \\
\hline M2 & 70 & 67,73 \\
\hline M3 & 80 & 75,28 \\
\hline M4 & 90 & 78,86 \\
\hline M5 & 100 & 80,15 \\
\hline
\end{tabular}

Kết quả từ Bảng 1 cho thấy, khi nhiệt độ tăng lên thì mức độ đóng rắn tăng dần lền. Trong khoảng nhiệt độ từ $60-80^{\circ} \mathrm{C}$ mức độ đóng rắn tăng nhanh và tuyến tính theo nhiệt độ. Khi nhiệt độ sấy từ $80-100^{\circ} \mathrm{C}$, mức độ đóng rắn tăng chậm lại, mức độ đóng rắn không còn tăng tuyến tính theo nhiệt độ. Như vậy, nhiệt độ đóng rắn ảnh hưởng rất lớn đến mức độ đóng rắn hay nói cách khác ảnh hưởng rất lớn đến tính chất của vật liệu polyme compozit trên cơ sở nhựa nền epoxy $\mathrm{K}$ 153. Ở nhiệt độ trên $80^{\circ} \mathrm{C}$, mức độ đóng rắn tăng lên nhưng tốc độ hình thành các liên kết ngang càng cao, ứng suất nội cao hơn nên độ bền uốn và độ bền kéo đứt giảm xuống. Ngoài ra, nhiệt độ đóng rắn cao còn thúc đẩy quá trình lão hóa của vật liệu polyme compozit, do đó, làm suy giảm tính chất cơ lý của vật liệu [7]. Kết quả nghiên cứu cũng cho thấy, mức độ đóng rắn của nhựa epoxy K-153 thấp hơn nhiều so với nhựa epoxy thông thường (thông thường giá trị này $>$ $90 \%$ ) [2,3], do đó, làm tăng độ mềm dẻo của vật liệu PC, ngoài ra mức độ đóng rắn thấp có thể đã làm cho các phân tử dễ dàng trượt lên nhau trong quá trình biến dạng và làm tăng độ giãn dài khi đứt của vật liệu PC [3].

3.2. Khảo sát ảnh huởng của nhiệt độ sấy đến bền oxy hóa nhiệt của vật liệu polyme compozit

Để khảo sát ảnh hưởng của nhiệt độ sấy đến độ bền oxy hóa nhiệt của vật liệu polyme compozit trên cơ sở nhựa epoxy K-153 gia cường bằng sợi thủy tinh $\mathrm{T}-13$, sử dụng chất đóng rắn $\mathrm{PEPA}$, các mẫu $\mathrm{M}_{1}, \mathrm{M}_{2}, \mathrm{M}_{3}, \mathrm{M}_{4}, \mathrm{M}_{5}$ được gia công như bên trên. Phân tích nhiệt khối lượng (TGA) được thực hiện trên thiết bị NETZSCH TG 209F1 LIBRA. Điều kiện đo trong môi trường không khí với tốc độ nâng nhiệt $10^{\circ} \mathrm{C} /$ phút. Ảnh hưởng của nhiệt độ sấy đến độ bền oxy hóa nhiệt của vật liệu polyme compozit được thể hiện trong các Hình $1 \mathrm{a}, 1 \mathrm{~b}, 1 \mathrm{c}, 1 \mathrm{~d}, 1 \mathrm{e}$.

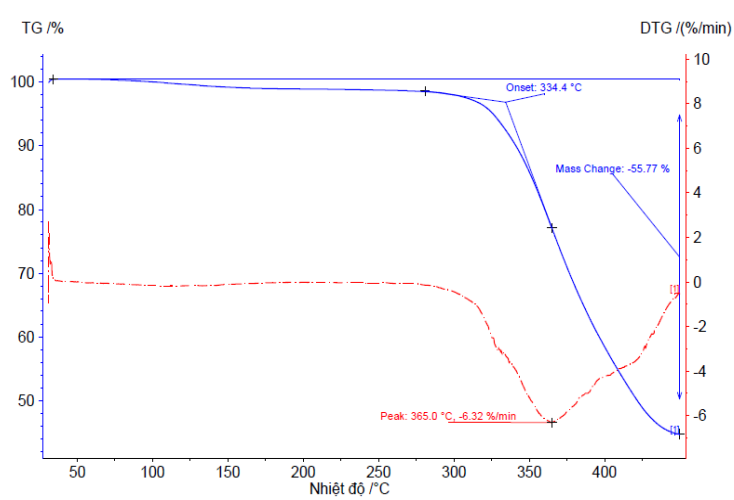

Hình 1a. Giản đồ phân tích nhiệt của mẫu vật liệu polyme compozit sấy ở $60^{\circ} \mathrm{C}$.

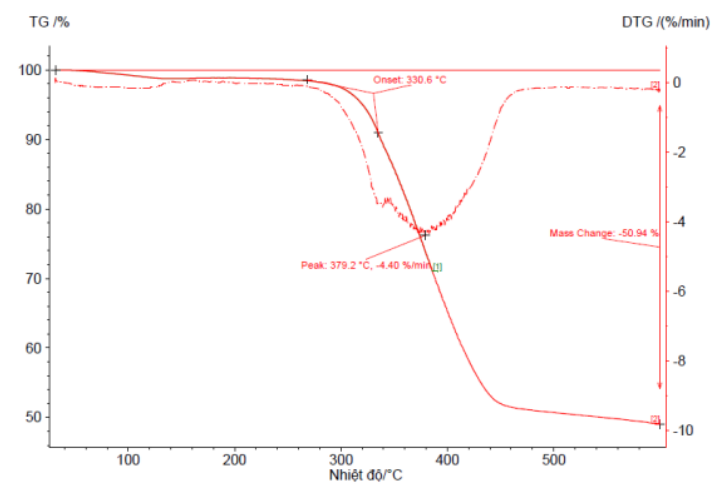

Hình 1b. Giản đồ phân tích nhiệt của mẫu vật liệu polyme compozit sấy ở $70^{\circ} \mathrm{C}$.

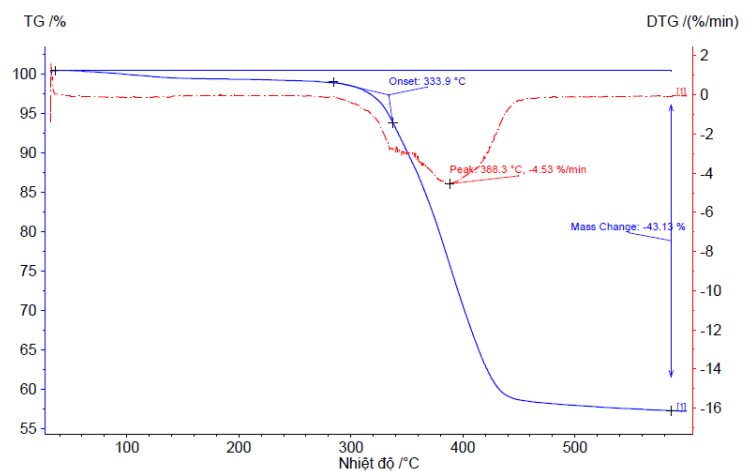

Hình 1c. Giản đồ phân tích nhiệt của mẫu vật liệu polyme compozit sấy ở $80^{\circ} \mathrm{C}$. 


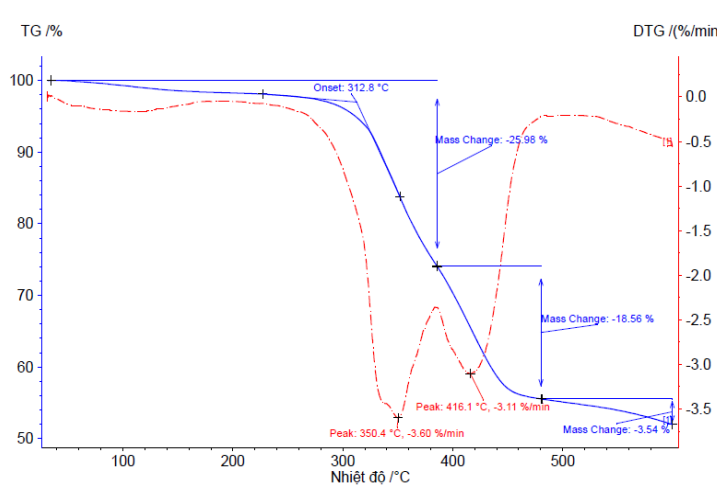

Hình 1d. Giản đồ phân tích nhiệt của mẫu vật liệu polyme compozit sấy ở $90^{\circ} \mathrm{C}$.

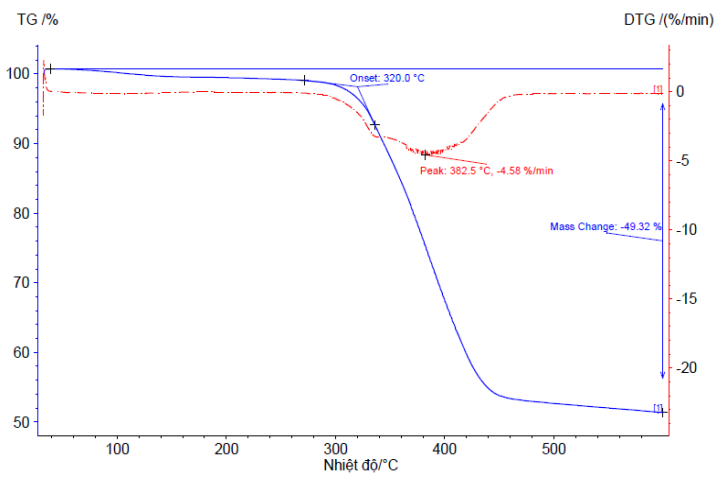

Hình 1e. Giản đồ phân tích nhiệt của mẫu vật liệu polyme compozit sấy ở $100^{\circ} \mathrm{C}$.

Kết quả phân tích nhiệt của các mẫu $\mathrm{M}_{1}$, $\mathrm{M}_{2}, \mathrm{M}_{3}, \mathrm{M}_{4}, \mathrm{M}_{5}$ cho thấy, có sự khác biệt về tốc độ và khối lượng mẫu bị tổn hao của các mẫu khảo sát. $M$ ẫu $\mathrm{M}_{1}$ kém bền oxy hóa nhiệt nhất. $\mathrm{Mẫu} \mathrm{M}_{3}$ có độ bền oxy hóa nhiệt cao nhất. Ở cùng điều kiện gia công, khi tăng nhiệt độ sấy thì độ bền oxy hóa nhiệt tăng lên, nếu tiểp tục tăng nhiệt độ sấy thì giá trị này lại giam xuống. Điều này có thể được giải thích như sau: khi nhiệt độ sấy thấp, thời gian sấy 06 giờ là chưa đủ để phản hết nhựa và chất đóng rắn, các liên kết ngang hình thành chưa nhiều, cấu trúc vật liệu không chặt chẽ, do đó, oxy dễ dàng xâm nhập vào trong vật liệu nên độ bền oxy hóa nhiệt của vật liệu thấp. Khi nhiệt độ sây tăng lên (đến khoảng $80^{\circ} \mathrm{C}$ ), tốc độ hình thành các liên kết ngang tăng lên liên kết của mạch đại phân tử chặt chẽ hơn ngăn cản sự xâm nhập của oxy vào trong vật liệu, từ đó ngăn cản quá trình phân hủy oxy hóa nhiệt của vật liệu nên độ bền oxy hóa nhiệt của vật liệu tăng lên. Tiếp tục tăng nhiệt độ sấy lên trên $80^{\circ} \mathrm{C}$, tốc độ hình thành các liên kết ngang tăng lên, sự xắp xếp các mạch đại phân tử kém trật tự hơn. Ngoài ra, nhiệt độ đóng rắn cao còn thúc đẩy quá trình lão hóa của vật liệu polyme compozit, do đó, làm suy giảm độ bền oxy hóa nhiệt và tính chất cơ lý của vật liệu [7, 8]. Các đặc trưng TGA của quá trình nghiên cứu được thể hiện ở Bảng 2.

Bảng 2. Các đặc trưng TGA của các mẫu polyme compozit thử nghiệm oxy hóa nhiệt

\begin{tabular}{|c|c|c|c|}
\hline \multirow{2}{*}{ Tên mẫu } & \multicolumn{3}{|c|}{$\begin{array}{c}\text { Khối lượng mẫu bị mất } \\
\text { ở các nhiệt độ khác nhau }(\%)\end{array}$} \\
\cline { 2 - 4 } & $275^{\circ} \mathrm{C}$ & $350^{\circ} \mathrm{C}$ & $450^{\circ} \mathrm{C}$ \\
\hline M1 & 1,42 & 13,95 & 55,77 \\
\hline M2 & 1,46 & 13,11 & 46,94 \\
\hline M3 & 1,45 & 10,21 & 42,35 \\
\hline M4 & 1,51 & 12,26 & 43,84 \\
\hline M5 & 1,55 & 12,74 & 45,82 \\
\hline
\end{tabular}

3.3. Khảo sát ảnh hưởng của nhiệt độ sấy đến bền nhiệt của vật liệu polyme compozit

Để khảo sát ảnh hưởng của nhiệt độ sấy đến độ bền nhiệt của vật liệu polyme compozit trên cơ sở nhựa epoxy K-153 gia cường bằng sợi thủy tinh $\mathrm{T}-13$, sử dụng chất đóng rắn PEPA. Các mẫu được ký hiệu $\mathrm{M}_{1}, \mathrm{M}_{2}, \mathrm{M}_{3}, \mathrm{M}_{4}, \mathrm{M}_{5}$ được gia công như bên trên. Phân tích nhiệt khối lượng (TGA) được $\mathrm{t}$ hực hiện trên thiết bị NETZSCH TG 209F1 LIBRA. Điều kiện đo trong môi trường khí nitơ với tốc độ nâng nhiệt $10^{\circ} \mathrm{C} /$ phút. Ảnh hưởng của nhiệt độ sấy đến độ bền nhiệt của vật liệu polyme compozit được thể hiện trong các Hình 2a, 2b, 2c, 2d, 2e.

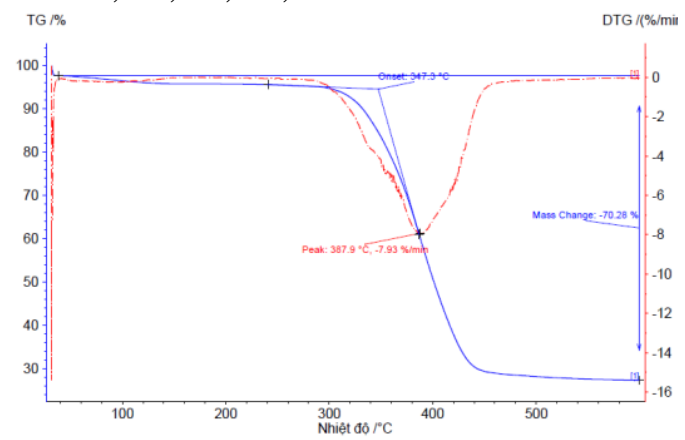

Hình 2a. Giản đồ phân tích nhiệt của mẫu vật liệu polyme compozit sấy ở $60^{\circ} \mathrm{C}$. 


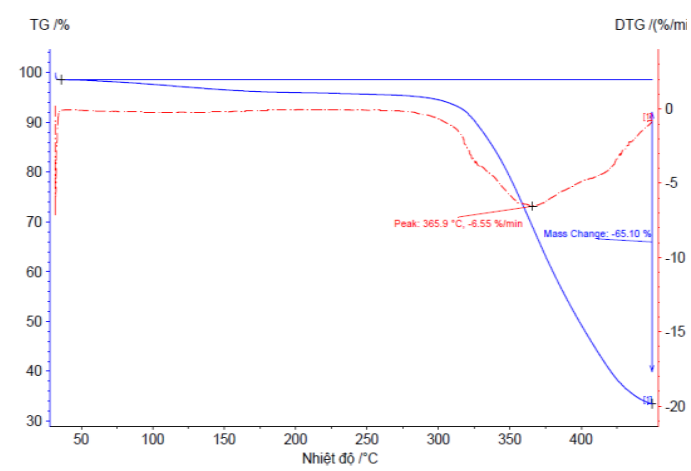

Hình 2b. Giản đồ phân tích nhiệt của mẫu vật liệu polyme compozit sấy ở $70^{\circ} \mathrm{C}$.

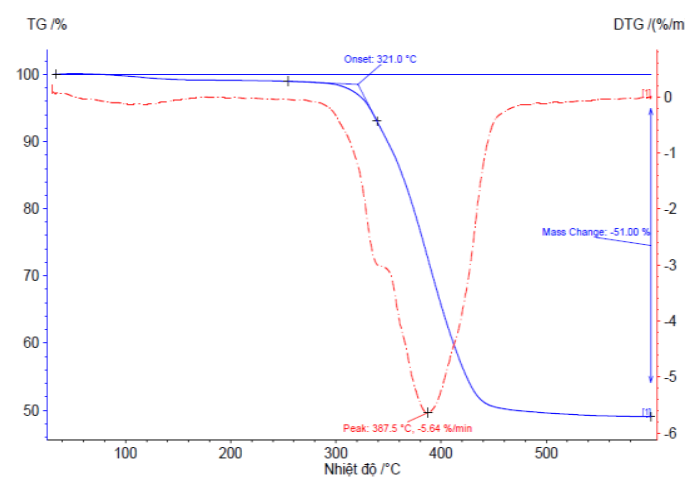

Hình 2c. Giản đồ phân tích nhiệt của mẫu vật liệu polyme compozit sấy ở $80^{\circ} \mathrm{C}$.

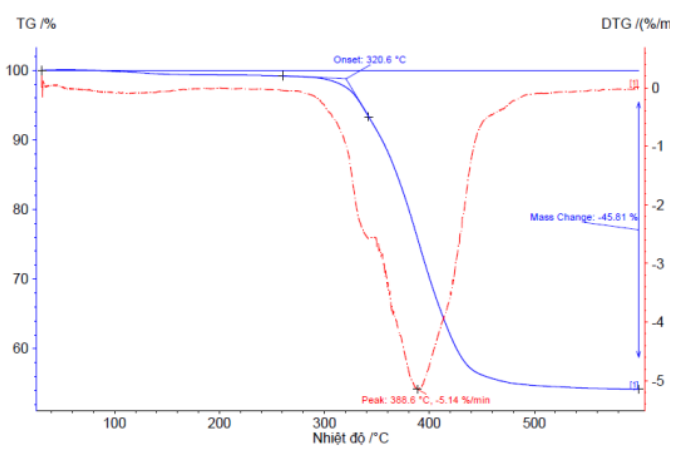

Hình 2 d. Giản đồ phân tích nhiệt của mẫu vật liệu polyme compozit sấy ở $90^{\circ} \mathrm{C}$

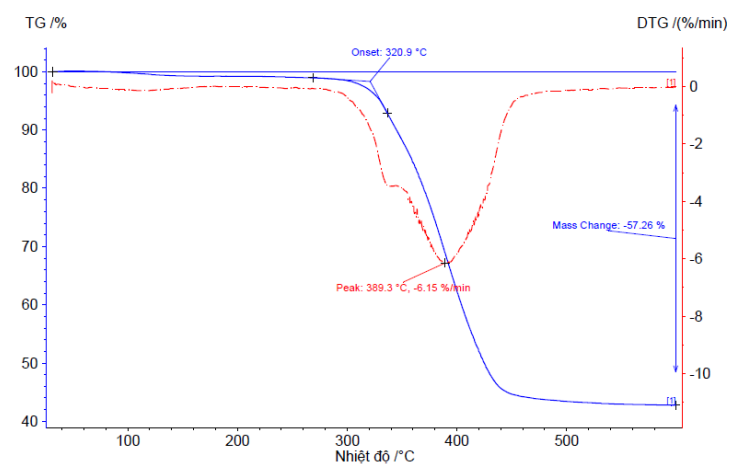

Hình 2e. Giản đồ phân tích nhiệt của mẫu vật liệu polyme compozit sấy ở $100^{\circ} \mathrm{C}$.

Kết quả phân tích nhiệt của các mẫu $\mathrm{M}_{1}, \mathrm{M}_{2}$, $\mathrm{M}_{3}, \mathrm{M}_{4}, \mathrm{M}_{5}$ cho thấy có sự khác biệt về khối lượng mẫu bị tổn hao. Ở nhiệt độ $500^{\circ} \mathrm{C}$, mẫu $\mathrm{M}_{1}$ có khối lượng tổn hao lớn nhất $(70,28 \%)$, mẫu $\mathrm{M}_{3}$ có độ bền nhiệt cao nhất, khối lượng tổn hao thấp nhất $(45,81 \%)$. Ở cùng điều kiện về thời gian gia công, khi tăng nhiệt độ sấy thì độ bền nhiệt tăng lên. Điều này có thể được giải thích như đối với độ bền oxy hóa nhiệt của vật liệu. Khi nhiệt độ sấy tăng lên, tốc độ hình thành các liên kết ngang tăng lên, liên kết của mạch đại phân tử chặt chẽ hơn, ngăn cản quá trình phân hủy nhiệt của vật liệu nên độ bền nhiệt của vật liệu tăng lên [9]. Tương tự như đối với độ bền oxy hóa nhiệt của vật liệu, khi tăng nhiệt độ sấy lên trên $80^{\circ} \mathrm{C}$, độ bền nhiệt của vật liệu lại giảm xuống. Các đặc trưng TGA của quá trình thử nghiệm bền nhiệt được thể hiện ở Bảng 3 .

Bảng 3. Các đặc trưng TGA của các mẫu polyme compozit thử nghiệm bền nhiệt

\begin{tabular}{|c|c|c|c|}
\hline \multirow{2}{*}{ Tên mẫu } & \multicolumn{3}{|c|}{$\begin{array}{c}\text { Khối lượng mẫu bị mất } \\
\text { ớ các nhiệt độ khác nhau }(\%)\end{array}$} \\
\cline { 2 - 4 } & $275^{\circ} \mathrm{C}$ & $350^{\circ} \mathrm{C}$ & $450^{\circ} \mathrm{C}$ \\
\hline M1 & 4,02 & 15,57 & 69,78 \\
\hline M2 & 4,05 & 14,72 & 65,10 \\
\hline M3 & 4,07 & 12,21 & 44,62 \\
\hline M4 & 4,08 & 12,52 & 49,64 \\
\hline M5 & 4,09 & 12,55 & 55,82 \\
\hline
\end{tabular}


3.4. Khảo sát ảnh hưởng của nhiệt độ sấy đến hìn thái cấu trúc của vật liệu polyme compozit

Để nghiên cứu ảnh hưởng của nhiệt độ sấy đến sự liên kết pha và hình thái cấu trúc của vật liệu polyme compozit, đã tiến hành chụp ảnh hiển vi điện tử quét (SEM) của các mẫu $\mathrm{M}_{1}, \mathrm{M}_{2}$, $\mathrm{M}_{3}, \mathrm{M}_{4}, \mathrm{M}_{5}$. Kết quả thu được thể hiện trên các Hình 3a, 3b, 3c, 3d, 3e.

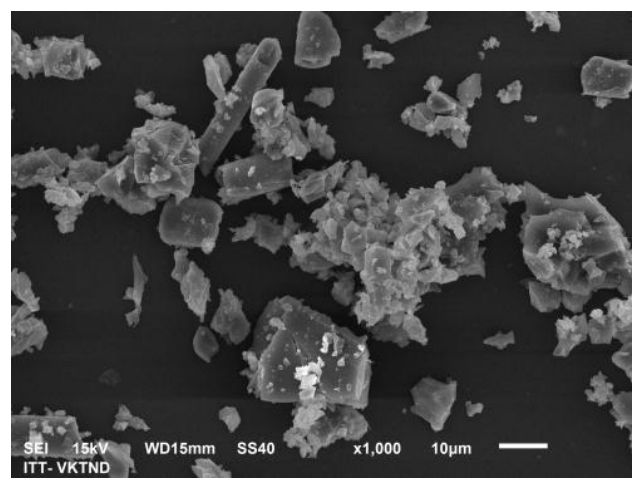

Hình 3a. Ảnh SEM của mẫu vật liệu polyme compozit sấy ở $60^{\circ} \mathrm{C}$.

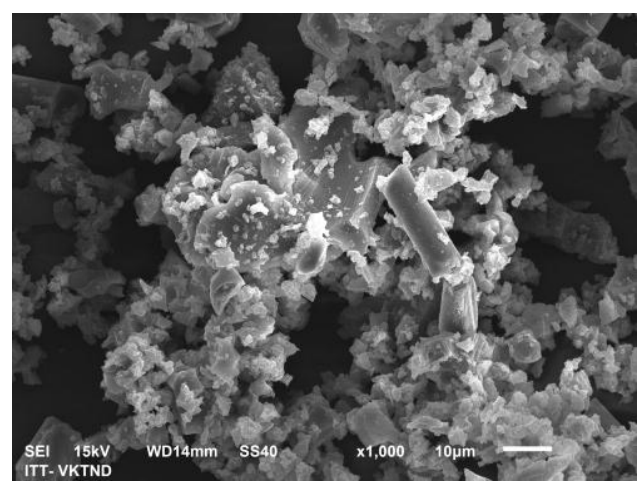

Hình 3b. Ảnh SEM của mẫu vật liệu polyme compozit sấy ở $70^{\circ} \mathrm{C}$.

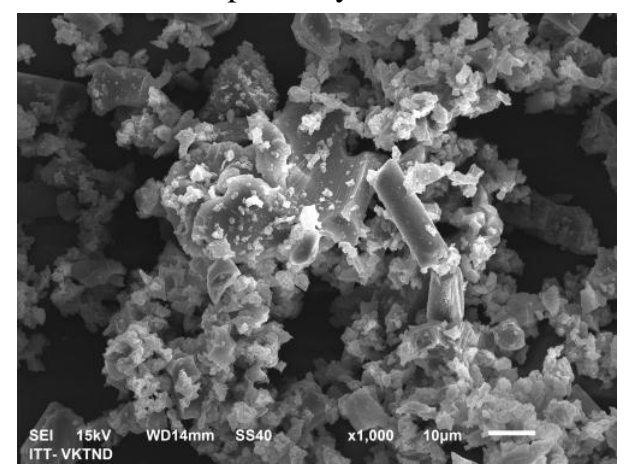

Hình 3c. Ảnh SEM của mẫu vật liệu polyme compozit sấy ở $80^{\circ} \mathrm{C}$.

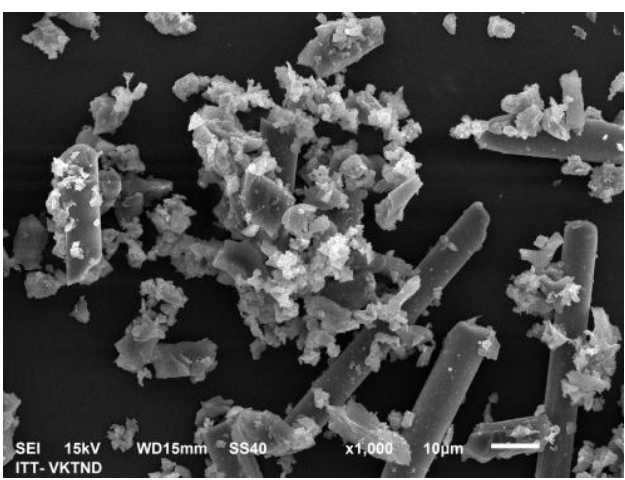

Hình 3d. Ảnh SEM của mẫu vật liệu polyme compozit sấy ở $90^{\circ} \mathrm{C}$.

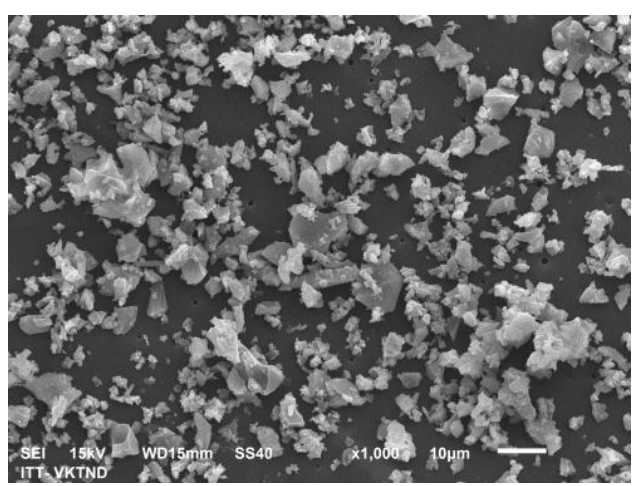

Hình 3e. Ảnh SEM của mẫu vật liệu polyme compozit sấy ở $100^{\circ} \mathrm{C}$.

Từ kết quả khảo sát tại các Hình $3 \mathrm{a}, 3 \mathrm{~b}, 3 \mathrm{c}$, $3 \mathrm{~d}, 3 \mathrm{e}$ cho thấy, hình thái cấu trúc vật liệu không khác nhau nhiều, điều này là do ở nhiệt độ sấy $60-100^{\circ} \mathrm{C}$ trong thời gian 06 giờ nhựa nền đã bám dính tốt với sợi thủy tinh, điều này có thể được giải thích là do nhựa epoxy K-153 có độ nhớt thấp nên góc tiếp xúc giữa vật liệu nền và vật liệu gia cường nhỏ, sức căng bề mặt thấp, do đó, làm tăng khả năng kết dính với nhựa nền polyme tại bề mặt phân chia pha [10].

\section{Kết luận}

- Nhiệt độ sấy tăng lên thì mức độ đóng rắn của của polyme compozit tăng lên. Trong khoảng nhiệt độ từ $60-80^{\circ} \mathrm{C}$ mức độ đóng rắn tăng nhanh và tuyến tính theo nhiệt độ. Khi nhiệt độ sấy từ $80-100^{\circ} \mathrm{C}$, mức độ đóng rắn tăng chậm 
lại, mức độ đóng rắn không tăng tuyến tính theo nhiệt độ.

- Các mẫu polyme compozit có cùng điều kiện gia công, khi tăng nhiệt độ sấy từ $60-100^{\circ} \mathrm{C}$ thì độ bền oxy hóa nhiệt, độ bền nhiệt tăng lên.

- Hình thái cấu trúc vật liệu polyme compozit không khác nhau nhiều khi các mẫu sau gia công được sấy ở nhiệt độ $60-100^{\circ} \mathrm{C}$ trong thời gian 06 giờ, khả năng kết dính giữa nhựa nền và vật liệu gia cường tốt.

- Đối với vật liệu polyme compozit trên cơ sở nhựa epoxy K-153 sử dụng chất đóng rắn PEPA (tỷ lệ: 100 PKL nhựa epoxy, 10 PKL PEPA), nhiệt độ sấy thích hợp là $80^{\circ} \mathrm{C}$ trong thời gian 06 giờ.

\section{Tài liệu tham khảo}

[1] M.J. Mochane, T.C. Mokhena, T.H. Mokhothu, A. Mtibe, E.R. Sadiku, S.S. Ray, I.D. Ibrahim, O.O. Daramola, Recent progress on natural fiber hybrid composites foradvanced applications: A review, eXPRESS Polymer Letters 13 (2019) 159-198.

[2] Jungseok Kim, Hyuk-Jin Yoon, Kwang-Bok Shin, A study on crushing behaviors of composite circular tubes with different reinforcing fibers, International Journal of Impact Engineering 38 (2014) 198-207.

[3] Ming Qiu Zhang, Min Zhi Rong, Self healing polymers and polymer composites, John Wiley \& Sons, Inc, New York, 2011.
[4] Vitalii Bezgin, Agata Dudek, Composites based on high-molecular weigh epoxy resin modified with polysulfide rubber, Composite Theory and practice 17 (2017) 79-83.

[5] A. Zubeldia, M. Larrran aga, P. Remiro, Fracture Toughening of Epoxy Matrices with Blends of Resins of Different Molecular Weights and Other Modifiers, Journal of Polyme Science Part B: Polymer Physics 42 (2004) 3920-3933. https:// doi.org/10.1002/polb.10675.

[6] TU 6-05-1584-85, Technical Specifications of epoxy resin K-153.

[7] Nguyen Trung Thanh, Effect of Technological Factors on some Properties of Composite tube with Epoxy Resin K-153 Matrix, VNU Journal of Science: Natural Sciences and Technology 35 (2019) 80-85. http://doi.org/10.25073/2588-1140/ vnunst.4895. (In Vietnamese).

[8] Byoung Un Kang, Jae Young Jho, Junkyung Kim, Effect of molecular weight between crosslinks on the fracture behavior of rubber-toughened epoxy adhesives, Journal of Application Polymer Science 79 (2001) 38-48. https://doi.org/10.1002/ 1097-4628(20010103)79:1<38::AID-PP50 > 3.0. $\mathrm{CO} ; 2-\mathrm{O}$

[9] D. Ratna, A.K. Banthia, P.C. Deb, AcrylateBased Liquid Rubber as Impact Modifier For Epoxy Resin, Journal of Application Polymer Science 80 (2001) 1792-1801. https://doi.org/10. 1002/app.1275.

[10] Hossein Yahyaie, Morteza Ebrahimi, Hamed Vakili Tahami, Ehsan R. Mafi, Toughening mechanisms of rubber modified thin film epoxy resins, Progress in Organic Coatings 76 (2013) 286-292. https://doi.org/10.1016/j.porgcoat.2012. 09.016 . 